\title{
A computational study of base-catalyzed reactions of cyclic 1,2-diones: cyclobutane-1,2-dione
}

\author{
Nargis Sultana ${ }^{1,2}$ and Walter M. F. Fabian ${ }^{* 2}$
}

\section{Full Research Paper}

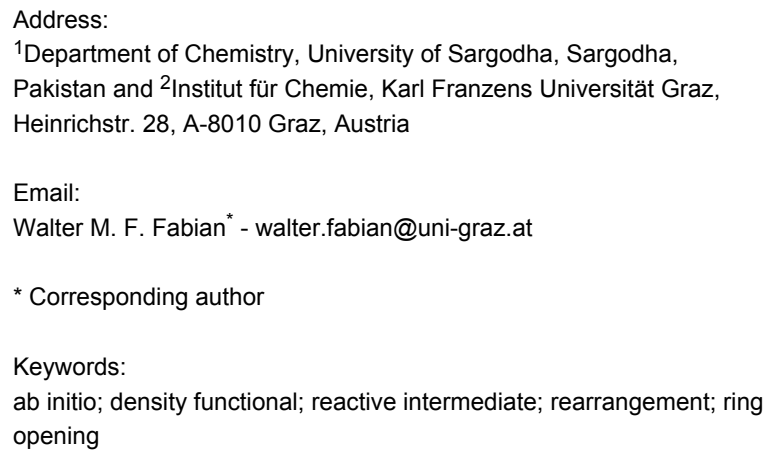

${ }^{1}$ Department of Chemistry, University of Sargodha, Sargodha, Pakistan and ${ }^{2}$ Institut für Chemie, Karl Franzens Universität Graz, Heinrichstr. 28, A-8010 Graz, Austria

Email:

Walter M. F. Fabian* - walter.fabian@uni-graz.at

* Corresponding author

Keywords:

ab initio; density functional; reactive intermediate; rearrangement; ring opening

Beilstein J. Org. Chem. 2013, 9, 594-601.

doi:10.3762/bjoc.9.64

Received: 21 December 2012

Accepted: 25 February 2013

Published: 21 March 2013

This article is part of the Thematic Series "New reactive intermediates in organic chemistry".

Guest Editor: G. Bucher

(C) 2013 Sultana and Fabian; licensee Beilstein-Institut. License and terms: see end of document.

\begin{abstract}
The reaction of cyclobutane-1,2-dione with hydroxide was studied by a variety of ab initio (MP2, SCS-MP2, CCSD(T), CEPA/1) and density functional (M06-2X) methods. Three possible reaction paths of the initially formed tetrahedral adduct leading to either 1-hydroxycyclopropane-1-carboxylate (benzilic acid type rearrangement, path A), $\alpha$-oxobutanoate (path B) or $\gamma$-oxobutanoate (path C) were considered. Although the latter two products show similar or even more negative Gibbs free energies of reaction than calculated for the benzilic acid type rearrangement, the Gibbs free energies of activation are substantially higher. According to the calculations, the only feasible reaction appears to be the formation of 1-hydroxycyclopropane-1-carboxylate, which is corroborated by previous experimental observations.
\end{abstract}

\section{Introduction}

Addition of nucleophiles, e.g., $\mathrm{OH}^{-}$, to 1,2-dicarbonyl compounds leads to the formation of relatively stable tetrahedral adducts (Scheme 1) [1]. These adducts further react either by (i) fission of the $\mathrm{R}^{2}-\mathrm{C}$ bond and migration of $\mathrm{R}^{2}$ (benzil-benzilic acid rearrangement, path $\mathrm{A}$ ); (ii) fission of the $\mathrm{R}^{2}-\mathrm{C}$ bond without migration of $\mathrm{R}^{2}$ resulting in $\alpha$-oxocarboxylic acids (path B); or (iii) fission of the carbonyl-C- $-\mathrm{sp}^{3}-\mathrm{C}$ with formation of an aldehyde and carboxylic acid (path $\mathrm{C}$ ). In the case of benzils, depending on the substituents on the aryl rings, all three types of reactions have been observed [2].

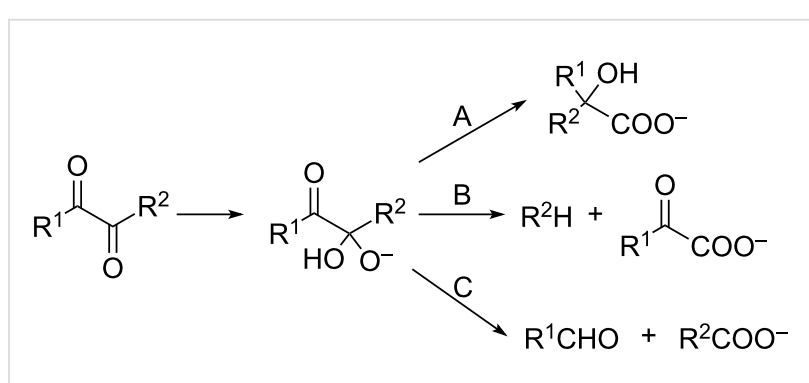

Scheme 1: Reactions of 1,2-dicarbonyl compounds with base. 
The benzilic acid rearrangement of cyclic 1,2-diones [3,4] leads to ring contraction, e.g., the rearrangement of cyclobutane-1,2dione (1) to 1-hydroxycyclopropanecarboxylate (2) [5-7]. In contrast, cyclobut-3-ene-1,2-diones 3 react to 2-oxobut-3enoates 4 (at least formally according to path B) [8], whereas benzocyclobutene-1,2-diones 5 lead to 2-formylbenzoates 6 (path C, Scheme 2) [9].

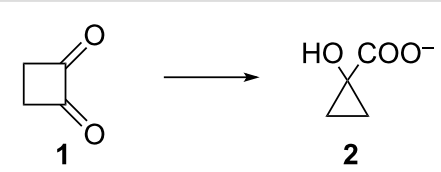<smiles>O=c1c([Al])c([Al])c1=O</smiles>

3<smiles>Cc1ccccc1C</smiles>

5<smiles>[13C]/C=C(\Br)C(=O)C(=O)[O-]</smiles><smiles>O=Cc1ccccc1C(=O)[O-]</smiles>

Scheme 2: Reactions of cyclic 1,2-diones with base.

In view of the importance of the benzil-benzilic acid rearrangement in organic chemistry, several computational studies concerning this rearrangement $[10,11]$ or related reactions (Favorskii rearrangement [12-14], halolactonisation [15]) have been published. To the best of our knowledge no attempt has been made so far to consider the additional pathways $\mathrm{B}$ and $\mathrm{C}$ in these reactions. Here we present a detailed computational study (DFT and ab initio) of the base-catalyzed reactions of cyclobutane-1,2-dione (1) taking into account all three possible pathways.

\section{Results and Discussion}

The various transition states, intermediates and products initially considered for the three reaction paths $\mathrm{A}, \mathrm{B}$, and $\mathrm{C}$ are depicted in Scheme 3. It turned out that not all of the structures shown in Scheme 3 could actually be located as stationary points on the potential-energy surface. On the other hand, some other stable as well as highly reactive intermediates and/or transition states were obtained (see below). Generally, in nucleophilic addition reactions to carbonyl compounds in aqueous solution, water not only acts as a solvent but frequently actively participates in the reaction, such as in water-assisted hydrolysis [16-20] or also in the benzil-benzilic acid rearrangement [11] Therefore, cyclobutane-1,2-dione (1) hydrated by two water molecules, and hydroxide ion hydrated by four, i.e., $\mathbf{1} \cdot\left(\mathrm{H}_{2} \mathrm{O}\right)_{2}$ and $\left[\mathrm{OH}\left(\mathrm{H}_{2} \mathrm{O}\right)_{4}\right]^{-}$, were used as reactants. Hence for all transition states, intermediates and products shown in Scheme 3, hydration by six water molecules is implied.

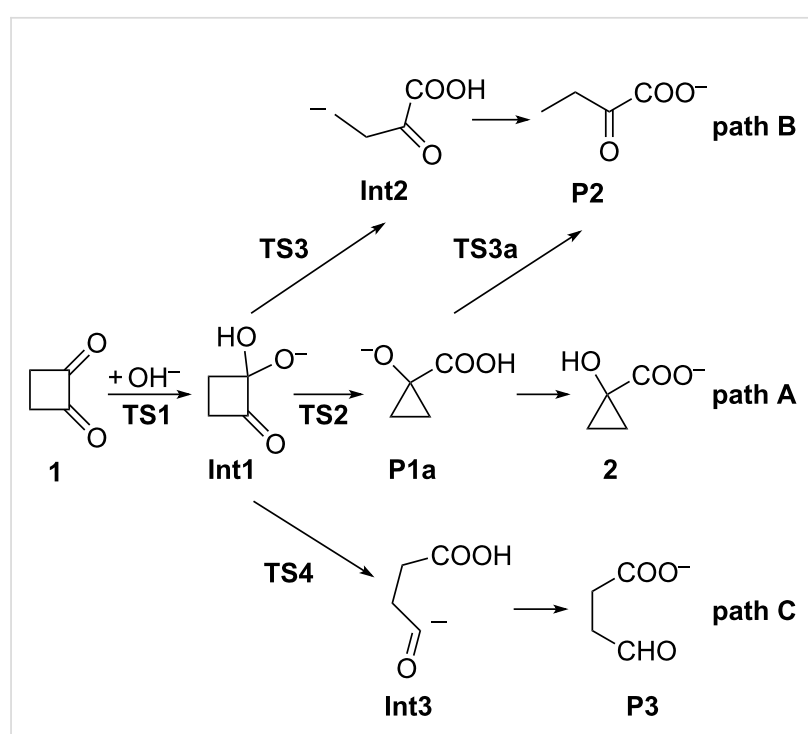

Scheme 3: Possible intermediates, transition structures, and products considered for the reaction of cyclobutane-1,2-dione with hydroxide anion.

Relative Gibbs free energies with respect to the separated reactants $\mathbf{1} \cdot\left(\mathrm{H}_{2} \mathrm{O}\right)_{2}+\left[\mathrm{OH}\left(\mathrm{H}_{2} \mathrm{O}\right)_{4}\right]^{-}$including bulk aqueous solvation energies (SMD solvation model [21]) obtained by various computational procedures are collected in Table 1. More detailed results are provided in Supporting Information File 1. Before discussing the individual reaction paths in detail, a comparison of the computational procedures used (M06-2X [22], MP2 [23] and SCS-MP2 [24], the composite energy scheme $E_{\mathrm{C}}=E(\mathrm{MP} 2 / 6-311+\mathrm{G}(2 \mathrm{df}, 2 \mathrm{p})+E\{[\mathrm{CCSD}(\mathrm{T})-\mathrm{MP} 2] / 6-$ $31+\mathrm{G}(\mathrm{d})\}$; and LPNO-CEPA/1 [25-27]) is made.

\section{Comparison of computational procedures}

Taking the CEPA/1 results as a reference, inspection of Table 1 reveals that all other computational procedures invariably lead to a greater stabilization of all stationary points considered with respect to the separated reactants. The largest deviation from the CEPA/1 energies is obtained with M06-2X, the smallest with SCS-MP2. The corresponding mean absolute deviations and RMS errors are 5.9, 6.3 (M06-2X); 3.6, 3.9 (MP2); 2.5, 2.9 (SCS-MP2); and 3.9, $4.0\left(E_{\mathrm{C}}\right)$. However, the predicted trends agree very well with that obtained with CEPA/1 [Supporting Information File 1; the corresponding correlation coefficients $R^{2}$ are 0.992 (M06-2X); 0.997 (MP2 and SCS-MP2); and 0.999 $\left(E_{\mathrm{C}}\right)$. Inclusion of an empirical dispersion correction (DFTD3 [28]) in the M06-2X results further lowers the relative energies by ca. $0.8 \mathrm{kcal} \mathrm{mol}^{-1}$.

Figure 1 summarizes the energetic as well as structural aspects of all three possible reaction paths in the reaction of cyclobutane-1,2-dione with hydroxide anions. 
Table 1: Relative Gibbs free energies for all stationary points considered $^{\text {a }}$.

\begin{tabular}{lrrrrr} 
& M06-2X & MP2 & SCS-MP2 & $E_{C}$ & CEPA/1 \\
\hline IDC & 2.5 & 4.2 & 6.7 & 3.7 & 7.3 \\
TS1 & 6.3 & 6.5 & 10.0 & 6.2 & 11.1 \\
Int1 & -6.1 & -4.4 & -4.1 & -5.8 & -2.2 \\
TS2 & 7.7 & 6.9 & 9.2 & 9.4 & 14.3 \\
P1a & -15.2 & -10.3 & -11.1 & -9.0 & -6.2 \\
2 & -32.6 & -28.6 & -29.9 & -28.2 & -24.4 \\
TS3a & 12.8 & 15.7 & 17.9 & 16.6 & 19.9 \\
P2 & -39.8 & -37.5 & -39.9 & -39.4 & -36.7 \\
TS4 & 16.4 & 17.6 & 20.2 & 17.6 & 22.2 \\
Int4 & 14.7 & 17.8 & 20.7 & 18.1 & 22.7 \\
TS5 & 34.3 & 38.7 & 41.0 & 36.7 & 42.2 \\
P3a & -29.3 & -23.7 & -23.1 & -23.7 & -21.2 \\
Int2a & -25.5 & -19.9 & -20.9 & -22.1 & -18.4 \\
P2a & -40.4 & -37.3 & -38.9 & -38.6 & -35.3 \\
\hline
\end{tabular}

${ }^{\mathrm{a}} \Delta \mathrm{G}\left(1 \mathrm{~mol} \mathrm{~L}^{-1}\right.$ standard state, $\left.\mathrm{kcal} \mathrm{mol}^{-1}\right)$ with respect to separated reactants $1 \cdot\left(\mathrm{H}_{2} \mathrm{O}\right)_{2}+\left[\mathrm{OH}\left(\mathrm{H}_{2} \mathrm{O}\right)_{4}\right]^{-}$. All geometries optimized with M06$2 X / 6-31+G(d, p)$. For M06-2X, MP2, and SCS-MP2 single-point calculations the $6-311+\mathrm{G}(2 \mathrm{df}, 2 \mathrm{p})$ basis set was used; LPNO-CEPA calculations were done with the def2-QZVPP basis set; $E_{C}=E[M P 2 / 6-$ $311+\mathrm{G}(2 \mathrm{df}, 2 \mathrm{p})]+E\{[\mathrm{CCSD}(\mathrm{T})-\mathrm{MP} 2] / 6-31+\mathrm{G}(\mathrm{d})\} ; \Delta \mathrm{G}_{\text {solv }}$ calculated by SMD M06-2X/6-31G(d).

\section{Individual reaction paths}

Addition of neutral nucleophiles to carbonyl compounds generally proceeds via formation of a prereaction complex; if Gibbs free energies instead of pure electronic energies or enthalpies are considered, such complexes usually become unstable [29]. In the present case without inclusion of bulk solvation effects (Supporting Information File 1) this prereaction complex (ion-dipole complex IDC) is quite stable with $\Delta G=-14$ to $-19 \mathrm{kcal} \mathrm{mol}^{-1}$ compared to the separated reactants. However, especially the large calculated [SMD-M06-2X/6-31G(d)] solvation energy of $\left[\mathrm{OH}\left(\mathrm{H}_{2} \mathrm{O}\right)_{4}\right]^{-}$compared with that of the ion-dipole complex $\left(\Delta G_{\text {solv }}=-66\right.$ versus $\left.-54 \mathrm{kcal} \mathrm{mol}^{-1}\right)$ results in an endergonic formation of this complex $(\Delta G=$ $2.5-7.3 \mathrm{kcal} \mathrm{mol}^{-1}$, Table 1). After passing transition state TS1 $\left(v=144 \mathrm{i} \mathrm{cm}^{-1}\right)$, formation of the tetrahedral adduct by attack of $\left[\mathrm{OH}\left(\mathrm{H}_{2} \mathrm{O}\right)_{4}\right]^{-}$at $\mathrm{C} 1$ leads to the first truly stable intermediate Int1. This intermediate is common to all further possible pathways. The nucleophile involved in the formation of Int1 actually is a water molecule, since formation of the $\mathrm{C} 1-\mathrm{O} 3$ bond is accompanied by proton transfer $\mathrm{H} 3$ to $\mathrm{O} 4$ of the original hydroxide anion (Figure 2). An analogous concerted addition-proton transfer has also been calculated previously for the benzilic acid type rearrangements of biacetyl and benzil [11]. Car-Parrinello molecular dynamics simulations of the hydrolysis of formamide in basic solution indicated that the traditional view of attack by hydroxide anion rather than a first-solvation-shell water molecule is more likely; however, the more powerful electrophile methyl formate should react according to the general-base mechanism [30]. The second carbonyl group in 1,2-diones efficiently enhances the carbonyl reactivity to make attack by water the preferred mode of reaction.

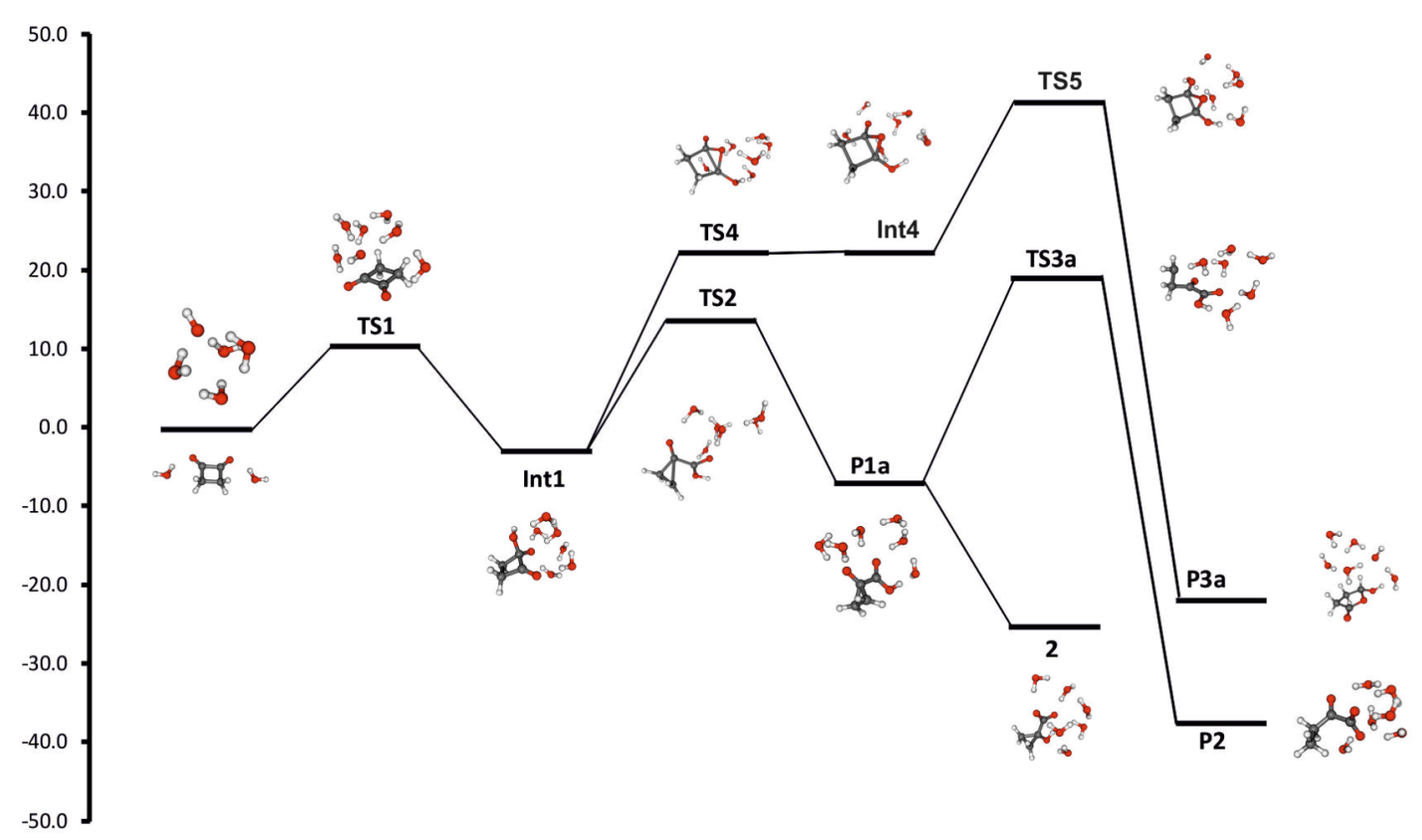

Figure 1: CEPA-1/def2-QZVPP calculated reaction paths for the reaction of $1 \cdot\left(\mathrm{H}_{2} \mathrm{O}\right)_{2}+\left[\mathrm{OH}\left(\mathrm{H}_{2} \mathrm{O}\right)_{4}\right]^{-}$. 


\section{TS1}

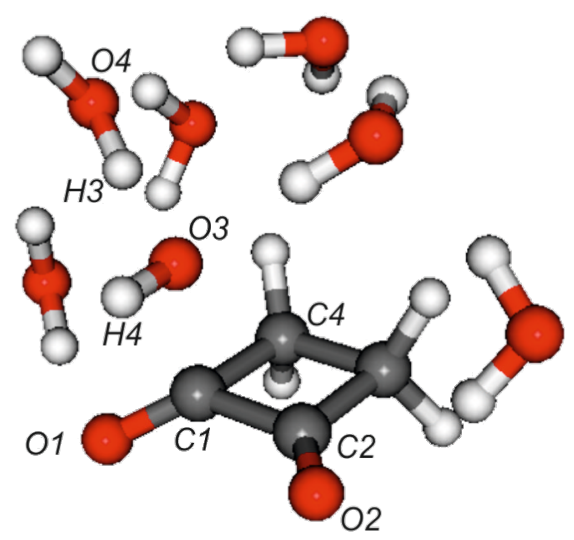

$r(C 1-01) \quad 1.234 \quad r(C 1-C 2) \quad 1.560$

$r(C 1-O 3) \quad 1.867 \quad r(C 2-O 2) \quad 1.205$

$r(\mathrm{O} 3-\mathrm{H} 3) \quad 1.464 \quad r(\mathrm{C} 1-\mathrm{C} 4) \quad 1.555$

\section{TS2}

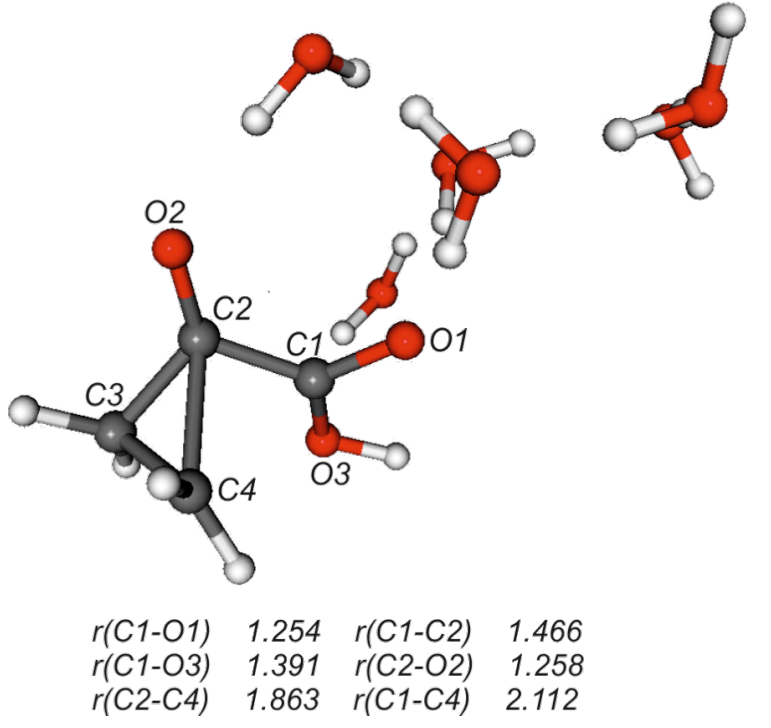

\section{Int1}

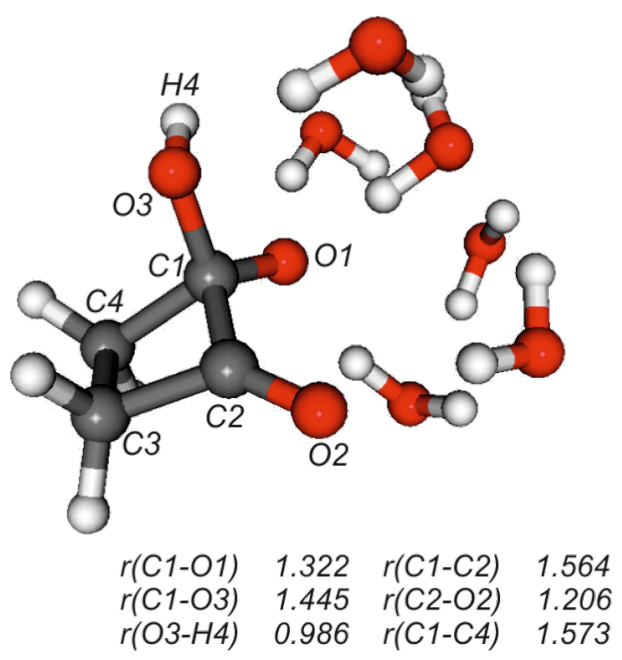

2

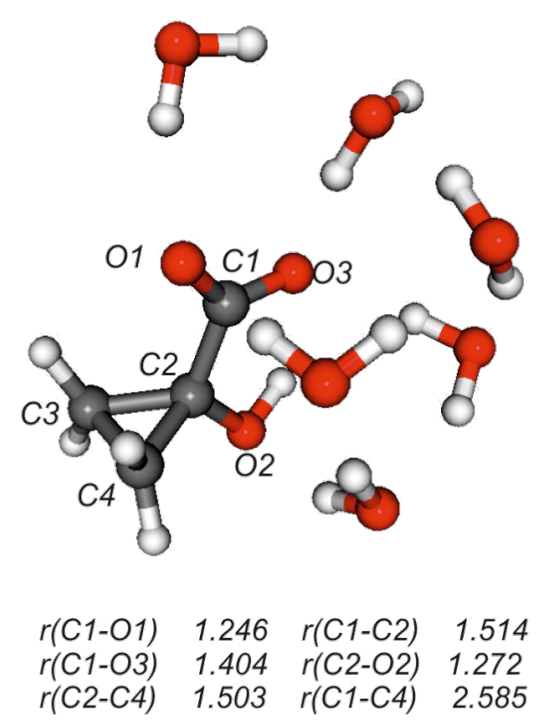

Figure 2: M06-2X/6-31+G(d,p) calculated structures of stationary points along the benzilic acid type rearrangement. Distances are given in angstroms $(\AA)$.

\section{Benzil-benzilic acid rearrangement (Path A)}

With respect to intermediate Int1, the Gibbs free energy of activation of the benzilic acid rearrangement (fission of the $\mathrm{C} 1-\mathrm{C} 4$ and concerted formation of the $\mathrm{C} 2-\mathrm{C} 4$ bond) via TS2 $\left(v=246 i \mathrm{~cm}^{-1}\right)$ is ca. $15 \mathrm{kcal} \mathrm{mol}^{-1}$. The initial product P1a (1-carboxycyclopropanolate) is expected to easily convert to the final product 1-hydroxycyclopropanecarboxylate (2) by a simple acid-base equilibrium (protonation of the alcoholate, deprotonation of the carboxylic acid, $\left.\Delta p K_{a} \sim 10\right)$. Overall, path A is not only strongly exergonic $\left[\Delta G_{\text {react }}=-24.4(\mathrm{CEPA} / 1)\right.$ to $\left.-33 \mathrm{kcal} \mathrm{mol}^{-1}(\mathrm{M} 06-2 \mathrm{X})\right]$ but has also a quite low barrier
$\left[\Delta G^{f}=6.9\right.$ (MP2) to $\left.14.3 \mathrm{kcal} \mathrm{mol}^{-1}(\mathrm{CEPA} / 1)\right]$, Table 1. Thus, this reaction should be quite feasible. Pertinent geometrical data are collected in Table S3 of Supporting Information File 1; M06-2X/6-31+G(d,p) optimized structures of relevant stationary points along path $\mathrm{A}$ are depicted in Figure 2.

The breaking $\mathrm{C} 1-\mathrm{C} 4$ bond is stretched from $1.573 \AA$ in Int1 to $2.112 \AA$ in TS2 $(2.585 \AA$ in 2$)$, while the newly formed bond C2-C4 is shortened from $2.125 \AA$ in Int1 to $1.863 \AA$ in TS2 ( $1.503 \AA$ in 2 ). The Wiberg bond indices resulting from an $\mathrm{NBO}$ analysis [31] for the $\mathrm{C} 1-\mathrm{C} 4$ bond are 0.92 (Int1) and 0.35 
(TS2); those for the $\mathrm{C} 2-\mathrm{C} 4$ bond are 0.04 (Int1) and 0.40 (TS2), indicating nearly equal bond breaking and formation. The feasibility of the carbanion [1,2]-shift in the benzilic acid rearrangement has been attributed to the special shape [11] of the LUMO of 1,2-dicarbonyl compounds.

\section{Path B}

Product $\mathbf{P 2}$ should be even more stable than $\mathbf{2}$. However, despite several attempts neither TS3 nor Int2 could be obtained. Instead, invariably TS2 or P1a were obtained. It is tempting to assume that the relatively close contact between $\mathrm{C} 2$ and $\mathrm{C} 4$ preferentially results in $\mathrm{C} 2-\mathrm{C} 4$ bond formation rather than addition of a proton to Int2. To address this problem, optimization of an extended conformation Int2' was attempted. However, such a structure collapsed upon geometry optimization in a concerted proton transfer-nucleophilic addition reaction to intermediate Int2a. By a simple acid-base equilibrium (alcoholate-carboxylic acid $\rightarrow$ alcohol-carboxylate), this intermediate is expected to convert immediately to product P2a, i.e., the hydrate of product $\mathbf{P 2}$ (Scheme 4).

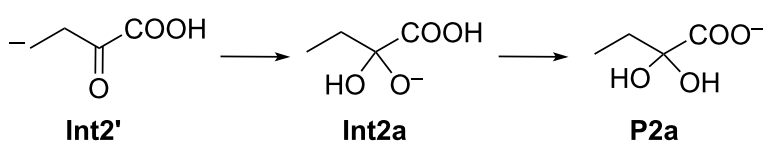

Scheme 4: Reaction sequence calculated for an extended conformation of Int2.

While all attempts to locate transition state TS3 as well as those ones leading to either Int2' or Int2a were unsuccessful, a path [TS3a $\left(v=410 i \mathrm{~cm}^{-1}\right.$, Scheme 3 and Figure 3] directly connecting P1a instead of Int1 with P2, could be obtained. Hence, path B actually does not start off from Int1 but diverges at the initially formed product P1a of path A.

Compared with TS2, transition state TS3a (Figure 3) is characterized by significantly longer $\mathrm{C} 1-\mathrm{C} 4$ and $\mathrm{C} 2-\mathrm{C} 4$ bonds, 2.975 and $2.259 \AA$ in TS3a versus 2.112 and $1.863 \AA$ in TS2. Similarly, the $\mathrm{C} 2-\mathrm{C} 3-\mathrm{C} 4$ angle and the $\mathrm{C} 1-\mathrm{C} 2-\mathrm{C} 3-\mathrm{C} 4$ dihedral angle are much larger in $\mathbf{T S 3 a}\left(96.7^{\circ}\right.$ and $\left.76.0^{\circ}\right)$ than those found in TS2 $\left(76.6^{\circ}\right.$ and $\left.54.8^{\circ}\right)$, Table S3 in Supporting Information File 1. The main "movement" in TS3a is transfer of a proton from $\mathrm{O} 4$ to $\mathrm{C} 4$; consequently the imaginary frequency of TS3a is larger $\left(v=410 i \mathrm{~cm}^{-1}\right)$ than that of TS2 $\left(v=246 i \mathrm{~cm}^{-1}\right)$ with $\mathrm{C}-\mathrm{C}$ bond formation as the associated mode.

\section{Path C}

Similar to path B, all attempts to locate the initially proposed intermediate Int3 were unsuccessful. Instead a more compli-

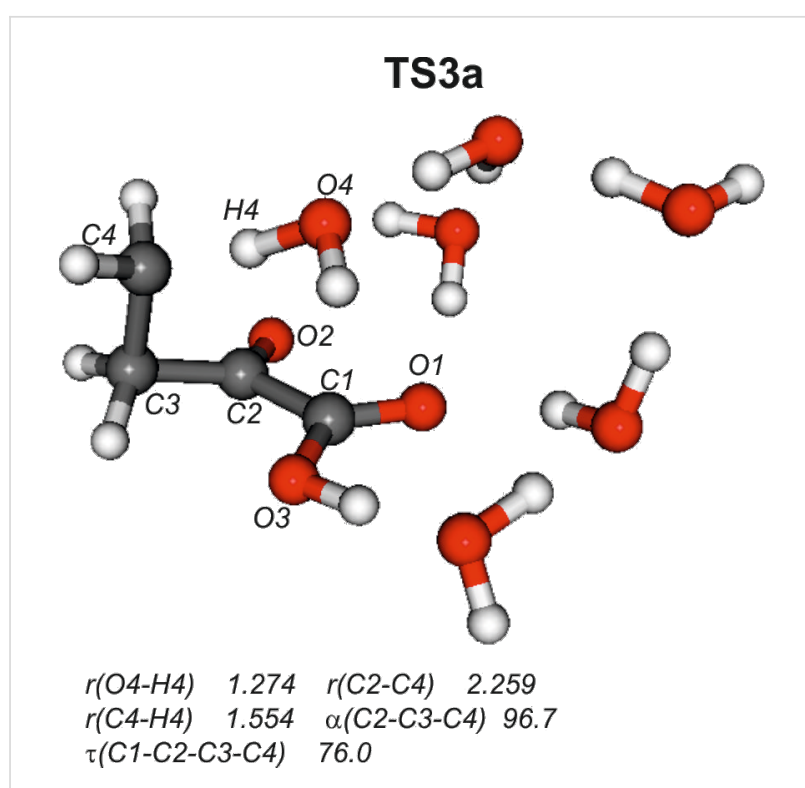

Figure 3: Calculated structure of transition state TS3a. Distances are given in angstrom $(\AA)$, angles in degrees.

cated pathway involving a high-energy bicyclic intermediate Int4 was found (Figure 4).

Furthermore, this intermediate did not react to product $\mathbf{P 3}$ but instead through a concerted ring opening and proton transfer to P3a. The anticipated product $\mathbf{P 3}$ of path $\mathrm{C}$ is a $\gamma$-oxocarboxylate. Such $\gamma$-oxocarboxylic acids or carboxylates are prone to ring-chain tautomerism [32,33]. Product P3a essentially is the ion-dipole complex between the ring tautomer of neutral $\gamma$-oxobutanoic acid with $\left[\mathrm{OH}\left(\mathrm{H}_{2} \mathrm{O}\right)_{5}\right]^{-}$, and hence, its formation is completely reasonable. The actual pathway $\mathrm{C}$ obtained by the calculations is indicated in Scheme 5 .

In fact, Int4 is barely stable if Gibbs free energies and bulk aqueous solvation are taken into account (Table 1 and Supporting Information File 1) and should collapse more or less barrierless to the tetrahedral adduct Int1. In contrast, rearrangement to P3a involves a substantially higher barrier (40-45 kcal mol ${ }^{-1}$ with respect to Int1) than path A (ca. $15 \mathrm{kcal} \mathrm{mol}^{-1}$ with respect to Int1). TS4, Int4 and TS5 can be considered as bicyclic structures consisting of a 3-membered oxirane and a 4-membered cyclobutane ring. The two rings are inclined to each other as indicated by the angle $\alpha$ measured between the midpoints of the $\mathrm{C} 3-\mathrm{C} 4$ and $\mathrm{C} 1-\mathrm{C} 2$ bonds and the oxygen atom $\mathrm{O} 1\left[\alpha=103^{\circ}(\mathbf{T S 4}), 106^{\circ}\left(\right.\right.$ Int4), and $112^{\circ}$ (TS5)]. The product P3a of path $\mathrm{C}$ has a largely planar fivemembered ring structure $\left(\alpha=165^{\circ}\right)$. In both TS4 and Int4 the $\mathrm{C} 1-\mathrm{C} 2$ distance $(1.48 \AA)$ is in the range of $\mathrm{C}-\mathrm{C}$ single bonds, while in TS5 this bond is significantly stretched $(r=1.853 \AA$; in P3a this distance is $r=2.317 \AA$ ). In contrast the $\mathrm{O} 1-\mathrm{C} 2$ bond 


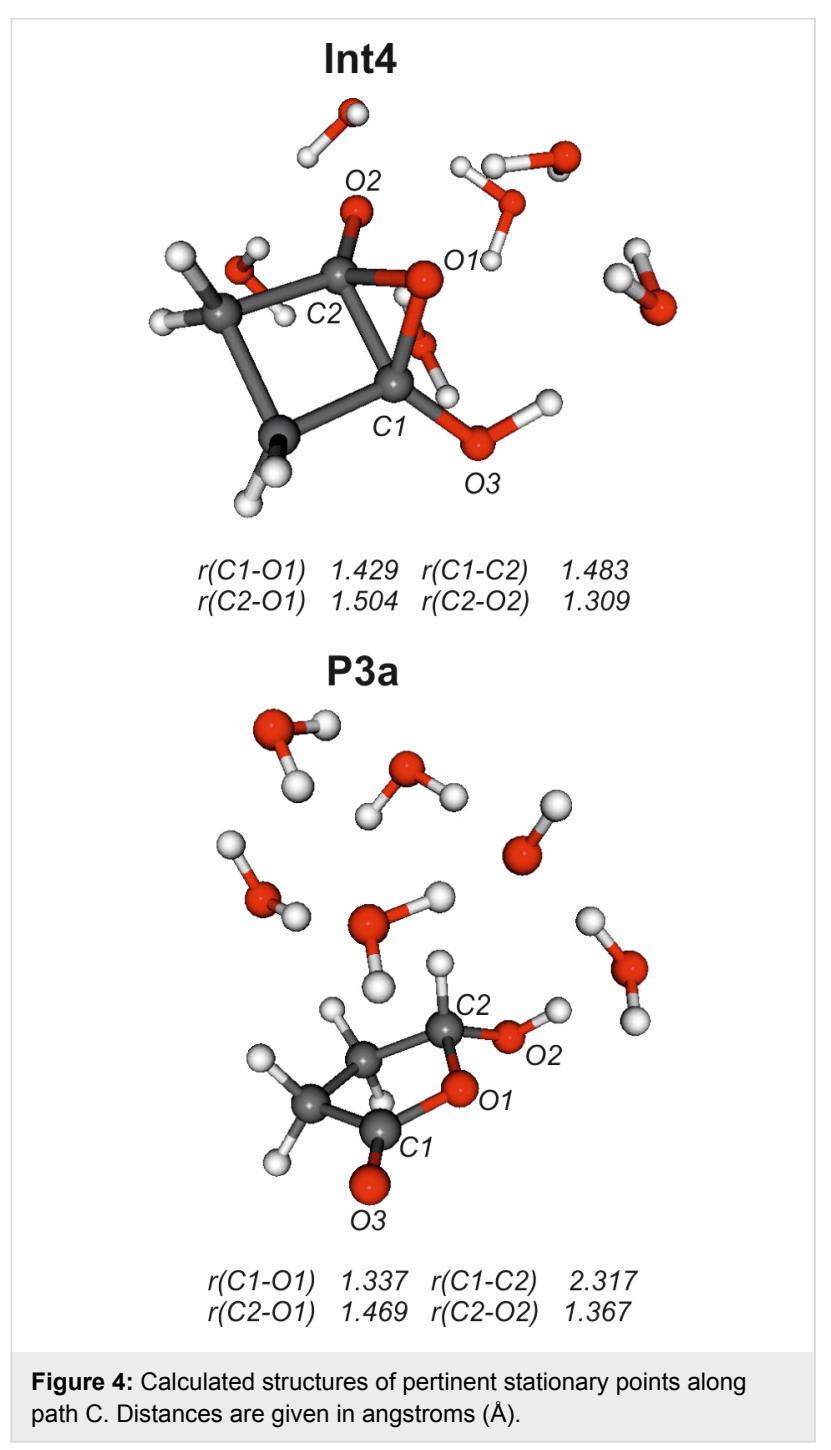

Scheme 5: Actual path $\mathrm{C}$ obtained by the calculations (as in Scheme 3, Int1, TS4, Int4, and TS5 are hydrated by six water molecules; P3a is the ion-dipole complex with $\left[\mathrm{OH}\left(\mathrm{H}_{2} \mathrm{O}\right)_{5}\right]^{-}$).

is shortened, i.e., $1.747 \AA$ (TS4), $1.504 \AA$ (Int4), and $1.385 \AA$ (TS5), with a concomitant lengthening of the $\mathrm{C} 1-\mathrm{O} 1$ bond, i.e., $1.396 \AA$ (TS4), $1.429 \AA$ (Int4), and $1.531 \AA$ (TS5). In the product P3a the proton of the $\mathrm{O} 3-\mathrm{H}$ group is transferred by involving the whole water chain to oxygen atom $\mathrm{O} 2$. This change in the position of the proton is accompanied by a shortening and lengthening, respectively, of the $\mathrm{C} 1-\mathrm{O} 3$ and $\mathrm{C} 2-\mathrm{O} 2$ distances: in TS5 $r(\mathrm{C} 1-\mathrm{O} 3)=1.383 \AA$ and

$r(\mathrm{C} 2-\mathrm{O} 2)=1.233 \AA$, while in P3a $r(\mathrm{C} 1-\mathrm{O} 3)=1.210 \AA$ and $r(\mathrm{C} 2-\mathrm{O} 2)=1.367 \AA$. Finally, it should be noted that intermediates of the type Int4 have been proposed [9] to be involved in the base-catalyzed reactions of benzocyclobutenediones (reaction $\mathbf{5} \rightarrow \mathbf{6}$ in Scheme 2).

\section{Conclusion}

$\mathrm{Ab}$ initio (MP2, SCS-MP2, composite energy approach $E_{\mathrm{C}}$, LPNO-CEPA/1) and density functional methods (M06-2X) were applied to study the reaction of cyclobutane-1,2-dione in basic solution. The reaction system was modeled by using cyclobutane-1,2-dione hydrated with two water molecules and $\left[\mathrm{OH}\left(\mathrm{H}_{2} \mathrm{O}\right)_{4}\right]^{-}$as the nucleophilic reagent. Three possible reaction pathways were considered, namely (i) a benzilic acid type rearrangement (path A); (b) ring-opening of the bond between an aliphatic carbon and that bearing the added $\mathrm{OH}^{-}$group (path $\mathrm{B}$ ); and (c) fission of the bond between the carbonyl carbon and that bearing the added $\mathrm{OH}^{-}$group (path C). Attempts to locate path B starting directly from the tetrahedral intermediate Int1 were unsuccessful. Instead, a reaction sequence diverging from the initially formed product P1a of path A was found. Path C involved transformations via high energy bicyclic transition states and/or intermediates. The final products of these latter two paths have comparable (path $\mathrm{C}$ ) or even substantially more negative reaction energies (path B). However, the corresponding Gibbs free energies of activation are quite large. With respect to Int1 these are at the CEPA/1 level $22.2 \mathrm{kcal} \mathrm{mol}^{-1}$ (path B; with respect to P1a $\Delta G^{\neq}=44.3 \mathrm{kcal} \mathrm{mol}^{-1}$ ) and $44.4 \mathrm{kcal} \mathrm{mol}^{-1}$ (path C). In contrast, path A is not only strongly exergonic but also has a significantly lower activation energy, $\Delta G_{\text {react }}=-22.2 \mathrm{kcal} \mathrm{mol}^{-1}$ and $\Delta G^{\neq}=16.5 \mathrm{kcal} \mathrm{mol}^{-1}$ with respect to Int1.

Hence, in agreement with experimental observations [5-7], cyclobutane-1,2-dione is calculated to react via benzilic acid rearrangement to the ring-contracted product, i.e., 1-hydroxycyclopropanecarboxylate (2).

\section{Computational details}

Geometries were optimized by using the M06-2X density functional [22] and the $6-31+\mathrm{G}(\mathrm{d}, \mathrm{p})$ basis set $[34,35]$ and characterized by frequency calculations as minima or transition states. For transition states, IRC calculations [36] were also done. These geometries were then used for M06-2X, MP2 [23] and SCS-MP2 [24] single-point calculations using the 6-311+G(2df,2p) basis set [37]. For coupled cluster CCSD(T) [38] and CEPA-1 [25-27] calculations the 6-31+G(d) and def2QZVPP [39] basis sets, were used, respectively. Initial coordinates for $\left[\mathrm{OH}\left(\mathrm{H}_{2} \mathrm{O}\right)_{4}\right]^{-}$were taken from the WATER27 subset of the GMTKN30 database $[40,41]$ and reoptimized with M06$2 \mathrm{X} / 6-31+\mathrm{G}(\mathrm{d}, \mathrm{p})$. $\left[\mathrm{OH}\left(\mathrm{H}_{2} \mathrm{O}\right)_{4}\right]^{-}$was then placed about $6 \AA$ 
above $\mathbf{1} \cdot(\mathrm{H} 2 \mathrm{O})_{2}$ and the combined system again optimized, resulting in the ion-dipole complex. An initial structure for TS1 was obtained from a relaxed (i.e., optimization of all other coordinates) potential energy scan of the $\mathrm{OH}$-carbonyl-carbon distance; this structure was then refined by transition-state optimization and further characterized by IRC calculations along both directions of the normal mode corresponding to the imaginary frequency. The final structures of both IRC calculations were then completely optimized. An analogous procedure, usually considering several possible reaction coordinates, was used for an initial guess of all other transition states. Bulk solvent effects (aqueous solution) were obtained by the SMD solvent model [21] at the M06-2X/6-31G(d) computational procedure. Frequencies obtained at the M06-2X/6-31+G(d,p) level are unscaled. Gibbs free energies are given relative to the separated reactants $\mathbf{1} \cdot\left(\mathrm{H}_{2} \mathrm{O}\right)_{2}$ and $\left[\mathrm{OH}\left(\mathrm{H}_{2} \mathrm{O}\right)_{4}\right]^{-}$and contain a $1.9 \mathrm{kcal} \mathrm{mol}^{-1}$ correction for the standard state conversion $1 \mathrm{~atm}$ to $1 \mathrm{~mol} \mathrm{~L}^{-1}$ at $T=298.15 \mathrm{~K}$. Dispersion corrections to the M06-2X results were added by Grimme's DFTD3 procedure [28]. Programs used were ORCA [42], Gaussian 09 [43], GAMESS [44], and DFTD3 [45]; MOLDEN [46] and MOLEKEL [47] were used for structure building and visualization.

\section{Supporting Information}

\section{Supporting Information File 1}

Detailed computational results and plot of MP2, SCS-MP2 and M06-2X vs. CEPA $\Delta G_{\text {rel }}$ values, pertinent structural data, and Cartesian coordinates of all stationary structures. [http://www.beilstein-journals.org/bjoc/content/ supplementary/1860-5397-9-64-S1.pdf]

\section{Acknowledgements}

Nargis Sultana thanks the Higher Education Commission of Pakistan for the PhD scholarship.

\section{References}

1. Bowden, K.; Fabian, W. M. F. J. Phys. Org. Chem. 2001, 14, 794-796. doi:10.1002/poc.433

2. Bowden, K.; Williams, K. D. J. Chem. Soc., Perkin Trans. 2 1994, 77-81. doi:10.1039/p29940000077

3. Selman, S.; Eastham, J. F. Q. Rev., Chem. Soc. 1960, 14, 221-235. doi:10.1039/QR9601400221

4. Collins, C. J.; Eastham, J. F. Rearrangements involving the carbonyl group. In The Carbonyl Group: Volume 1; Patai, S., Ed.; PATAI'S Chemistry of Functional Groups; John Wiley \& Sons: New York, NY, 1966; pp 761-821. doi:10.1002/9780470771051

5. Bloomfield, J. J.; Ireland, J. R. S.; Marchand, A. P. Tetrahedron Lett. 1968, 9, 5647-5650. doi:10.1016/S0040-4039(00)70742-8

6. Scharf, H.-D.; Droste, W.; Liebig, R. Angew. Chem., Int. Ed. Engl. 1968, 7, 215-216. doi:10.1002/anie.196802151
7. de Groot, A.; Oudman, D.; Wynberg, H. Tetrahedron Lett. 1969, 10, 1529-1531. doi:10.1016/S0040-4039(01)87936-3

8. Al-Najjar, A.; Bowden, K.; Horri, M. V. J. Chem. Soc., Perkin Trans. 2 1997, 993-996. doi:10.1039/a606412d

9. Bowden, K.; Horri, M. V. J. Chem. Soc., Perkin Trans. 2 1997, 989-992. doi:10.1039/a606310a

10. Marques, C. S.; Ramalho, J. P. P.; Burke, A. J. J. Phys. Org. Chem. 2009, 22, 735-739. doi:10.1002/poc.1509

11. Yamabe, S.; Tsuchida, N.; Yamazaki, S. J. Org. Chem. 2006, 71, 1777-1783. doi:10.1021/jo051862r

12. Castillo, R.; Andrés, J.; Moliner, V. J. Phys. Chem. B 2001, 105, 2453-2460. doi:10.1021/jp003264g

13. Moliner, V.; Castillo, R.; Safont, V. S.; Oliva, M.; Bohn, S.; Tuñón, I.; Andrés, J. J. Am. Chem. Soc. 1997, 119, 1941-1947. doi:10.1021/ja962571q

14. Tsuchida, N.; Yamazaki, S.; Yamabe, S. Org. Biomol. Chem. 2008, 6, 3109-3117. doi:10.1039/b806577b

15. Buchanan, J. G.; Ruggiero, G. D.; Williams, I. H. Org. Biomol. Chem. 2008, 6, 66-72. doi:10.1039/b714118a

16. Cheshmedzhieva, D.; llieva, S.; Hadjieva, B.; Galabov, B. J. Phys. Org. Chem. 2009, 22, 619-631. doi:10.1002/poc.1492

17. Wolfe, S.; Shi, Z.; Yang, K.; Ro, S.; Weinberg, N.; Kim, C.-K. Can. J. Chem. 1998, 76, 114-124. doi:10.1139/v97-216

18. Barbosa, L. A. M. M.; van Santen, R. A. J. Mol. Struct.: THEOCHEM 2000, 497, 173-188. doi:10.1016/S0166-1280(99)00283-3

19. Haeffner, F.; Hu, C.-H.; Brinck, T.; Norin, T. J. Mol. Struct.: THEOCHEM 1999, 459, 85-93. doi:10.1016/S0166-1280(98)00251-6

20. Xiong, Y.; Zhan, C. J. Phys. Chem. A 2006, 110, 12644-12652. doi:10.1021/jp063140p

21. Marenich, A. V.; Cramer, C. J.; Truhlar, D. G. J. Phys. Chem. B 2009, 113, 6378-6396. doi:10.1021/jp810292n

22. Zhao, Y.; Truhlar, D. G. Acc. Chem. Res. 2008, 41, 157-167. doi:10.1021/ar700111a

23. Møller, C.; Plesset, M. S. Phys. Rev. 1934, 46, 618-622. doi:10.1103/PhysRev.46.618

24. Grimme, S. J. Chem. Phys. 2003, 118, 9095-9102. doi:10.1063/1.1569242

25. Liakos, D. G.; Neese, F. J. Phys. Chem. A 2012, 116, 4801-4816. doi:10.1021/jp302096v

26. Neese, F.; Wennmohs, F.; Hansen, A. J. Chem. Phys. 2009, 130, 114108. doi:10.1063/1.3086717

27. Neese, F.; Hansen, A.; Wennmohs, F.; Grimme, S. Acc. Chem. Res 2009, 42, 641-648. doi:10.1021/ar800241t

28. Grimme, S.; Antony, J.; Ehrlich, S.; Krieg, H. J. Chem. Phys. 2010, 132, 154104. doi:10.1063/1.3382344

29. Di Valentin, C.; Freccero, M.; Zanaletti, R.; Sarzi-Amadé, M. J. Am. Chem. Soc. 2001, 123, 8366-8377. doi:10.1021/ja010433h

30. Blumberger, J.; Ensing, B.; Klein, M. L. Angew. Chem. 2006, 118, 2959-2963. doi:10.1002/ange.200600283

31. Reed, A. E.; Curtiss, L. A.; Weinhold, F. Chem. Rev. 1988, 88, 899-926. doi:10.1021/cr00088a005

32. Valters, R. E.; Flitsch, W. Ring-Chain Tautomerism; Plenum Press: New York, NY, 1985. doi:10.1007/978-1-4684-4883-2

33. Fabian, W. M. F.; Bowden, K. Eur. J. Org. Chem. 2001, 303-309. doi:10.1002/1099-0690(200101)2001:2<303::AID-EJOC303>3.0.CO;2I

34. Hariharan, P. C.; Pople, J. A. Theor. Chim. Acta 1973, 28, 213-222. doi:10.1007/BF00533485 
35. Clark, T.; Chandrasekhar, J.; Spitznagel, G. W.; von Ragué Schleyer, P. J. Comput. Chem. 1983, 4, 294-301. doi:10.1002/jcc.540040303

36. Hratchian, H. P.; Schlegel, H. B. Finding minima, transition states, and following reaction pathways on ab initio potential energy surfaces. In Theory and Applications of Computational Chemistry. The First Forty Years; Dykstra, C. E.; Frenking, G.; Kim, K. S.; Scuseria, G. E., Eds.; Elsevier: Amsterdam, 2005; pp 195-249.

37. Lynch, B. J.; Zhao, Y.; Truhlar, D. G. J. Phys. Chem. A 2003, 107, 1384-1388. doi:10.1021/jp021590I

38. Bartlett, R. J. Wiley Interdiscip. Rev.: Comput. Mol. Sci. 2012, 2, 126-138. doi:10.1002/wcms.76

39. Weigend, F.; Ahlrichs, R. Phys. Chem. Chem. Phys. 2005, 7, 3297-3305. doi:10.1039/b508541a

40. GMTKN30; 2011, http://toc.uni-muenster.de/GMTKN/GMTKN30/GMTKN30main.html.

41. Bryantsev, V. S.; Diallo, M. S.; van Duin, A. C. T.; Goddard, W. A. J. Chem. Theory Comput. 2009, 5, 1016-1026. doi:10.1021/ct800549f 42. ORCA; 2010, http://www.mpibac.mpg.de/bac/logins/neese/description.php.

43. Gaussian 09, Revision A.02; Gaussian, Inc.: Wallingford, CT, 2009

44. Schmidt, M. W.; Baldridge, K. K.; Boatz, J. A.; Elbert, S. T.; Gordon, M. S.; Jensen, J. H.; Koseki, S.; Matsunaga, N.; Nguyen, K. A.; Su, S.; Windus, T. L.; Dupuis, M.; Montgomery, J. A. J. Comput. Chem. 1993, 14, 1347-1363. doi:10.1002/jcc.540141112

45. DFT-D3, Version 3.0 Rev 0; 2012, http://www.thch.uni-bonn.de/tc/index.php?section=downloads\&subsecti on=DFT-D3\&lang=english

46. Schaftenaar, G.; Noordik, J. H. J. Comput.-Aided Mol. Des. 2000, 14 123-134. doi:10.1023/A:1008193805436

47. MOLEKEL, 5.4.0.8; Swiss National Supercomputing Centre: Lugano, Switzerland, http://molekel.cscs.ch/wiki/pmwiki.php.

\section{License and Terms}

This is an Open Access article under the terms of the Creative Commons Attribution License (http://creativecommons.org/licenses/by/2.0), which permits unrestricted use, distribution, and reproduction in any medium, provided the original work is properly cited.

The license is subject to the Beilstein Journal of Organic Chemistry terms and conditions:

(http://www.beilstein-journals.org/bjoc)

The definitive version of this article is the electronic one which can be found at: doi:10.3762/bjoc.9.64 